\title{
REV ISTA
}

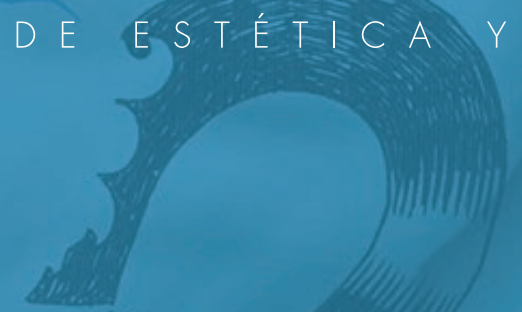

TEORIA

$D E$

LAS

A RTES

No $4 \cdot 2017 \cdot$ ISSN $2386-8449$

\section{CONVERSANDO CON}

"Más allá, pero aquí mismo", Entrevista con José Jiménez, por Miguel Salmerón Infante

UT PICTURA POESIS

Apuntes (1993-1998), Antonio Campillo

Dichoso aquel que no tiene patria, Poemas de Hannah Arendt, versiones de Anacleto Ferrer

PANOORAMA: ESTÉTICA DE LAS CREACIONES ESCÉNICAS Sección coordinada por Antonio Notario Ruiz

TEXTO INVITADO: O silêncio do tempo do silêncio, Fernando José Pereira

TEXTO. INVITADO: Ética y poética en el juego teatral de Reikiavik de Juan Mayorga, Zoe Martín Lago

El problema de la autonomía del teatro, Adrián Pradier Sebastián

¿Qué hubiera sido de Edipo sin Aristóteles y sin Freud? Sebastián Gámez Millán

Como actores en el gran teatro del mundo, Roger Ferrer Ventosa

Mahagonny: surrealismo y dialéctica de la anarquía. Apuntes desde T.W. Adorno, Marcelo Jaume Teruel

Nauman, Mirecka, Rainer: entre el cuerpo y el signo, Laura Maillo Palma

El espacio relativo de Newton y la trasformación de las prácticas escénicas en el teatro moderno, Raúl Pérez Andrade

Sturm und Drang. El drama del genio y Shakespeare, Milagros García Vázquez

MISCELÁNEA

Velázquez y el origen de la modernidad filosófica, Carlos M. Madrid Casado

Duchamp según Jean Clair vs. Arthur Danto, a 100 años de la Fuente, Andrea Carriquiry

Alegoría barroca e imagen dialéctica: el esfuerzo de Walter Benjamin y Theodor W. Adorno para pensar la dialéctica de la naturaleza y la forma estética, Vanessa Vidal Mayor

La idea de tradición en la estética de Jan Mukařovský, Raúl Sanz García

De la visión y el espanto: el tacto suspendido y la experiencia ante el límite, Rayiv David Torres Sánchez

Desrealizando el mundo objetivo: sobre la inmanencia de lo artístico en la fenomenología estética de M. Henry, Jaime Llorente Cardo

Estudios Visuales. Giros entre la crítica de la representación y la ciencia de la imagen, Sergio Martínez Luna

Épica en el arte: el caso de la cảnción de autor, Gustavo Sierra Fernández

El cine más allá de la narración de Lisandro Alonso, Horacio Muñoz Fernández

Perdidos en la isla de los prodigios: Lost o el abismo alegórico del drama barroco, Ainhoa Kaiero Clave

RESENAS

EDITA

\section{SEyTA.}

SOCIEDAD ESPAÑOLA
DE ESTETICAY TEORIA DE LAS ARTES 


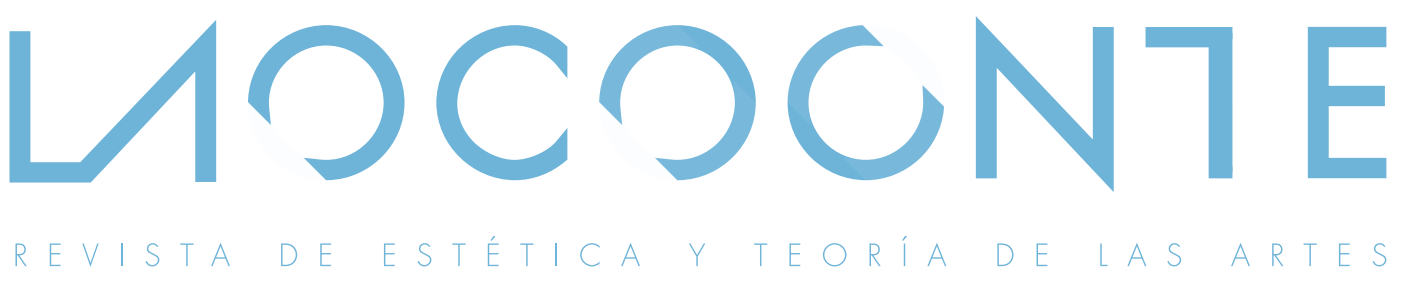

$\mathrm{N}^{\circ} 4 \cdot 2017$

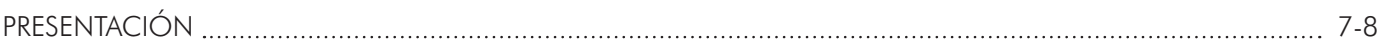

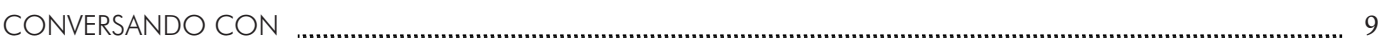

"Más allá, pero aquí mismo", Entrevista con José Jiménez, por Miguel Salmerón Infante .......................... 11-21

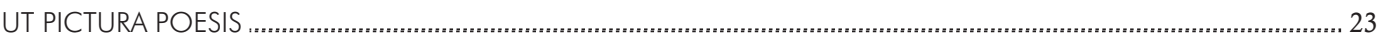

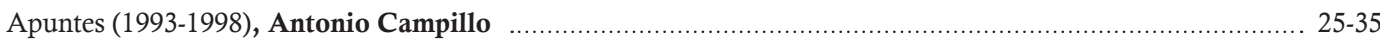

Dichoso aquel que no tiene patria, Poemas de Hannah Arendt, versiones de Anacleto Ferrer .............................. 37-49

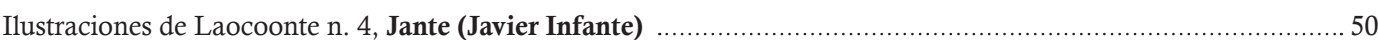

PANORAMA

ESTÉTICA DE LAS CREACIONES ESCÉNICAS _. _ _ _ _. sil

¿Qué hubiera pensado Wagner? Antonio Notario Ruiz (Coordinador) .......................................................... 53-55

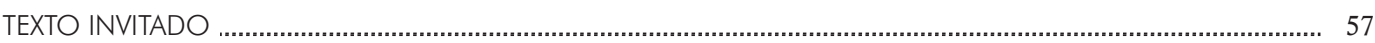

O silêncio do tempo do silêncio, Fernando José Pereira …....................................................................... 59-63

Ética y poética en el juego teatral de Reikiavik de Juan Mayorga, Zoe Martín Lago …..................................... 64-72

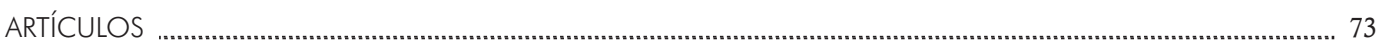

El problema de la autonomía del teatro, Adrián Pradier Sebastián . ....................................................... 75-92

¿Qué hubiera sido de Edipo sin Aristóteles y sin Freud? Sebastián Gámez Millán ........................................ 93-108

Como actores en el gran teatro del mundo, Roger Ferrer Ventosa ........................................................ 109-125

Mahagonny: surrealismo y dialéctica de la anarquía. Apuntes desde T.W. Adorno, Marcelo Jaume.Teruel... 126-133

Nauman, Mirecka, Rainer: entre el cuerpo y el signo, Laura Maillo Palma ............................................. 134-145

El espacio relativo de Newton y la trasformación de las prácticas escénicas en el teatro moderno,

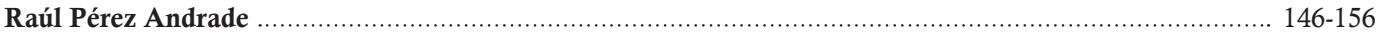

Sturm und Drang. El drama del genio y Shakespeare, Milagros García Vázquez ...................................... 157-168

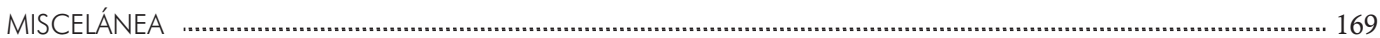

Velázquez y el origen de la modernidad filosófica, Carlos M. Madrid Casado .......................................... 171-181

Duchamp según Jean Clair vs. Arthur Danto, a 100 años de la Fuente, Andrea Carriquiry _ 18.…………... 182-198

Alegoría barroca e imagen dialéctica: el esfuerzo de Walter Benjamin y Theodor W. Adorno para pensar la dialéctica de la naturaleza y la forma estética, Vanessa Vidal Mayor .................................................... 199-213

La idea de tradición en la estética de Jan Mukařovský, Raúl Sanz García ................................................... 214-231

De la visión y el espanto: el tacto suspendido y la experiencia ante el límite, Rayiv David Torres Sánchez .... 232-240

Desrealizando el mundo objetivo: sobre la inmanencia de lo artístico en la fenomenología estética

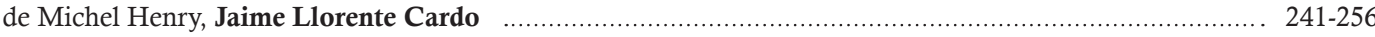


Estudios Visuales. Giros entre la crítica de la representación y la ciencia de la imagen,

Sergio Martínez Luna

Épica en el arte: el caso de la canción de autor, Gustavo Sierra Fernández

El cine más allá de la narración de Lisandro Alonso, Horacio Muñoz Fernández

Perdidos en la isla de los prodigios: Lost o el abismo alegórico del drama barroco, Ainhoa Kaiero Claver

RESEÑAS

Teorías del arte desde el siglo XXI, Pedro Lecanda Jiménez-Alfaro

Rimada Botánica, Xaverio Ballester

Sobre ciudades y arquitecturas, Jürgen Misch

Esbozo de una amistad sempiterna. Sobre Fuster y Alfaro, Raquel Baixauli

Cómo se analiza una obra de teatro, Teresa Aguado Garzón

Vuelan las imágenes, Verónica Perales Blanco

Mudanzas Espacio-temporales. Imagen y memoria, Raimon Ribera

$342-345$

Qué quieren las imágenes? Una crítica a la cultura visual, Esther González Gea

346-349

Zoos humanos, ethnic freaks y exhibiciones etnológicas, Lurdes Valls Crespo

350-353

España de la Guerra, Amanda del Rey Mateos

354-356

Benjamin, Barthes y la singularidad de la fotografía, Jorge Martínez Alcaide

$357-360$

Arte escrita: texto, imagen y género en el arte contemporáneo, Óscar Ortega Ruiz

$361-363$

Sobre el futuro del estudio del pasado, Ana Meléndez 364-366

Conducir a una diosa, Sergio Requejo Pérez

367-370

Cioran en los Archives paradoxales. (Tome III), Joan M. Marín

Género, memoria y cultura visual en el primer franquismo, Raquel Baixauli

La eternidad de un día, Carmen Martínez Sáez

Lo diabólico, lo demónico, lo fáustico en la literatura, la música y el arte, Mauro Jiménez

Circuit Circus. Circo, Intelectuales y Payasos, Ricard Silvestre

Ilustraciones de Jante (Javier Infante).

Fotografía de portada de Tamara Djermanovic intervenida con ilustración de Jante (Javier Infante). 


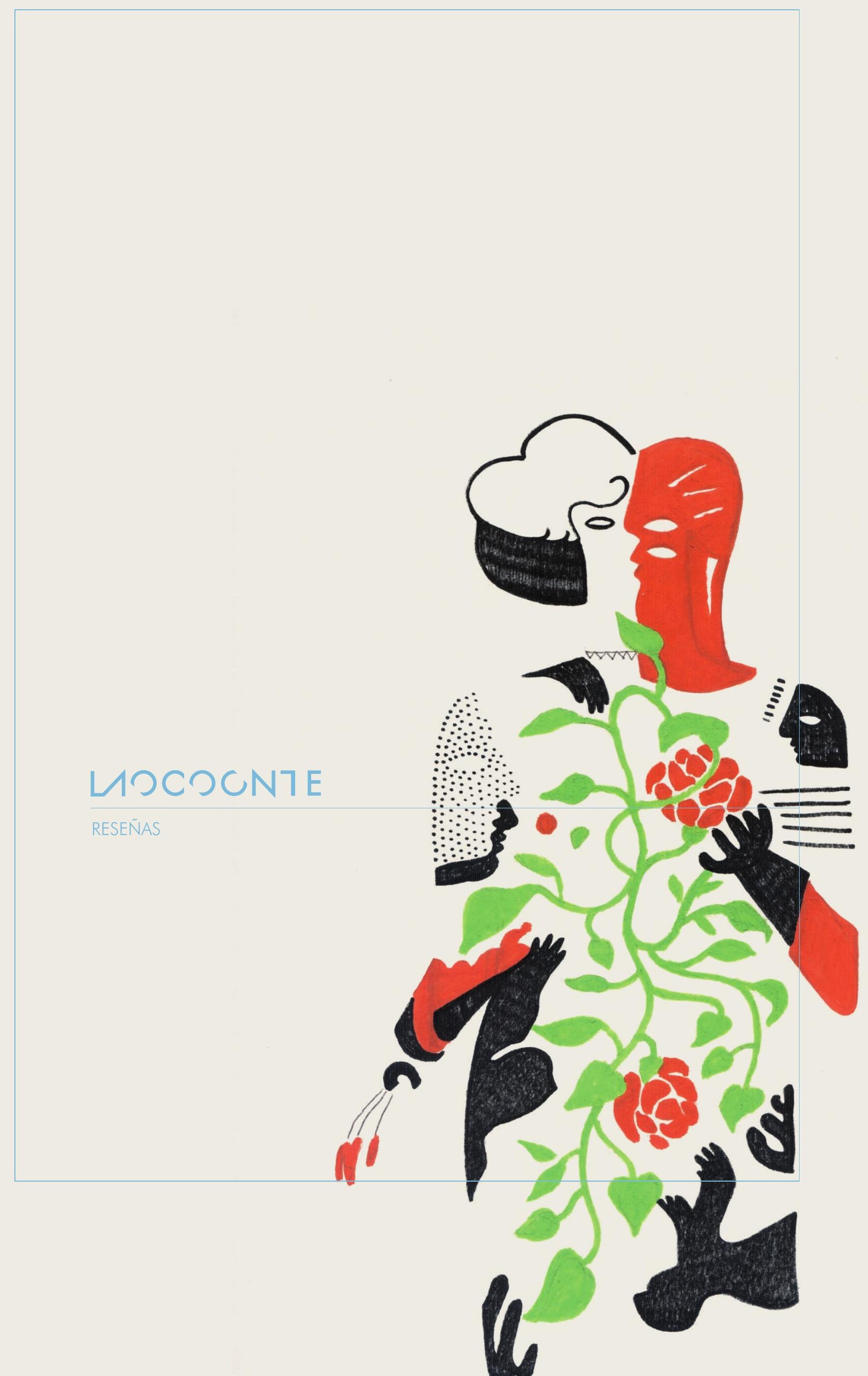




\title{
Arte escrita: texto, imagen y género en el arte contemporáneo
}

\author{
Óscar Ortega Ruiz*
}

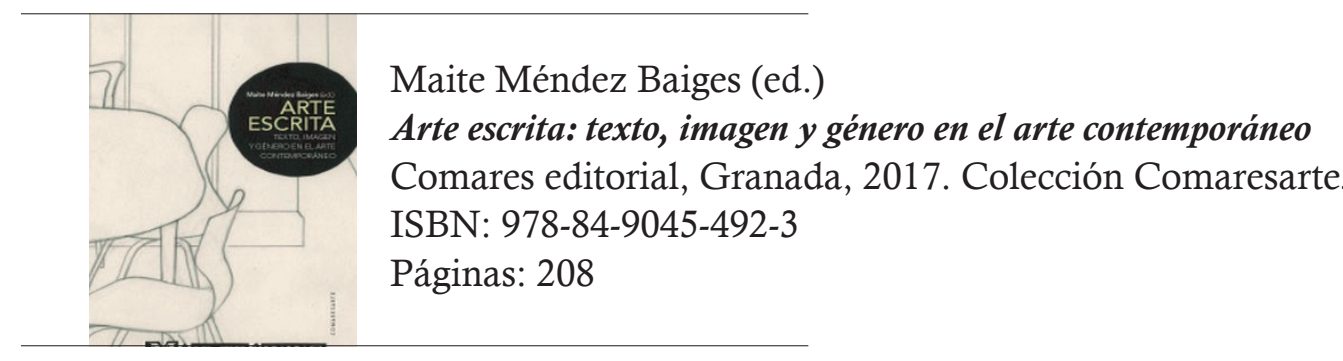

Arte escrita: texto, imagen y género en el arte contemporáneo es el título del nuevo volumen que la Editorial Comares ofrece a sus lectores dentro de la colección Comaresarte. E1 libro es fruto del trabajo colectivo de las investigadoras y el investigador del proyecto de I+D "Lecturas de la historia del arte contemporáneo desde la perspectiva de género", desarrollado por las Universidades de Málaga y de La Sapienza de Roma y se edita bajo la coordinación de Maite Méndez Baiges, responsable del programa de investigación y profesora titular de Arte moderno y contemporáneo en la Universidad de Málaga. El volumen se compone de ocho artículos o ensayos breves que, desde diversas perspectivas, dan cuenta del papel de la mujer a través del arte y la literatura de los últimos dos siglos, desarrollando la premisa de que los estudios de género constituyen una herramienta eficaz para disipar falsos mitos también en el ámbito del arte contemporáneo y, más específicamente, en la noción de vanguardia artística, más allá de las convenciones de lo que podría denominarse el "relato ortodoxo de la vanguardia". Las aportaciones y puntos de vista de las artistas del género femenino sirven como base para una exégesis alternativa a la tradicional, que se ha venido centrando en el paradigma del artista y receptor presuntamente universal pero, en realidad, sesgadamente masculino. Por otra parte, se analiza la imagen artística de la mujer proyectada por los medios artísticos, tanto literarios como visuales, como uno de los grandes focos de la construcción simbólica de lo femenino convencional.

Los primeros cuatro artículos nos introducen en el mundo artístico de una serie de autoras que, desde su condición de marginalidad femenina, supieron configurar un modernismo alternativo y antijerárquico que toma como uno de sus ejes creativos principales la visualidad del texto. La profesora Lidia Taillefer analiza la poesía visual de Marianne Moore, a la que cabría definir como una suerte de pintora de poemas. Figura central de la escena literaria neoyorquina durante la segunda década del XX, perteneció a la primera generación de poetas norteamericanos modernos, junto a T. S. Eliot, Ezra Pound y William Carlos Williams. Una autora para quien la literatura tenía una dimensión espiritual, que se trasluce en formas visuales que suponen un desafío

* $\quad$ Arquitecto por la Escuela Técnica Superior de Arquitectura de Sevilla; Licenciado en Filosofía por la Universidad de Málaga y Máster en Desarrollos Sociales de La Cultura Artística por la Universidad de Málaga. oscaror9@msn.com 
no sólo a la estilística sino también al propio lenguaje. Una síntesis entre lo verbal y lo óptico concebida por alguien para quien la apariencia visual constituye una prueba de calidad literaria. Claude Cahun y Marcel Moore son otras de las artistas que exploraron las posibilidades de enriquecimiento mutuo entre poesía y artes visuales, como destaca en su artículo la profesora Carmen Cortés Zahorras. Un binomio artístico creador de un entramado que enlaza los dibujos de la ilustradora Moore y los poemas de Cahun, de forma que las ilustraciones determinan una forma diferente de aprehender el texto escrito. Un juego de semejanzas y disimilitudes en el que relatos e ilustraciones juegan a parecerse y a ser diferentes. Para Cortés, esta imbricación de dos formas de expresión artística, consideradas entonces menores, es el resultado de la profunda modificación de las relaciones entre disciplinas que se produjo con el art nouveau y su empeño por aportar belleza a la cotidianeidad.

La profesora Esther Morillas analiza la obra de Kelly La Rocca, artista del Gruppo 70 que, a través de sus collages, se sirve de la estética y el lenguaje de la publicidad y, en general, de los medios de comunicación de masas, para desenmascarar su función de transmisores de códigos perpetuadores de situaciones de injusticia. La subversión que, en el plano artístico, realiza La Rocca de este tipo de lenguaje revela la falsedad de una supuesta liberación que, en realidad, aboca a la mujer a ser juzgada por su cuerpo y la obliga a la asunción de roles unificadores y secundarios, cuando no la define como un objeto más de consumo. El uso del lenguaje como instrumento de poder es también uno de los temas de reflexión del siguiente artículo, aportación de la profesora de la Universidad de La Sapienza, Carla Subrizi, quien traza un recorrido a través de los puntos de encuentro entre la literatura, las artes performativas y el feminismo con el comentario de la obra de artistas italianas como Niccolai, Vicinelli, Bentivoglio, Santoro y Lonzi. En Italia, destaca Subrizi, el arte de la performance nace y se desarrolla a partir de la investigación sobre la potencialidad de la palabra y el lenguaje poético. Se trata de una performance unida a la poesía, a la lectura y a la gestualidad del cuerpo. Un enfoque complejo, innovador y experimental en el que el lenguaje se fuerza más allá de sus límites en pro de nuevos órdenes discursivos, llevado a cabo por artistas que blanden palabras restituidas a la materialidad del cuerpo en contra de la hegemónica narración patriarcal.

La segunda mitad del libro nos desvía del dominio de la palabra para acercarnos a la visualidad de los códigos iconográficos. En su artículo, Maite Méndez Baiges aporta una serie de reflexiones suscitadas por la figura de la lectora en las primeras vanguardias del siglo XX, un tema objeto de múltiples representaciones artísticas. Ya en la Roma clásica, la lectora femenina aparece representada sola y absorta. A lo largo del siglo XIX aumenta el número de estas obras, con una notable proliferación de lectoras en una actitud que oscila entre la pasividad, como signo que revela disponibilidad sexual, y lo abiertamente voluptuoso. Esta visión de la imagen femenina se extiende también por la pintura de las primeras vanguardias, especialmente por el fauvismo, el cubismo y las tendencias expresionistas. En los años sesenta y setenta, autoras como Carol Duncan o Anna Chave, denunciarían no sólo el carácter sexista o incluso misógino de la pintura de estas primeras vanguardias, sino también la condición patriarcal del "relato ortodoxo de la modernidad" y su insistencia en el tema del desnudo femenino y su marcado erotismo, que denota una mirada acentuadamente masculina.

Si esta es la conclusión que cabe extraer del estudio de la representación de la mujer lectora en el arte de las vanguardias, la doctora Belén Ruiz Garrido nos aporta 
un análisis paralelo de las imágenes de escritoras en diversas representaciones artísticas contemporáneas. Autoras tan relevantes como Virginia Woolf son retratadas en la privacidad del hogar, formando parte del mobiliario de la casa casi como objetos, en lo que parece un intento de devaluarlas en su condición de creadoras. Mientras, el cine, las artes plásticas, la ilustración y la publicidad contribuyen a construir y difundir imágenes una mujer moderna presentada como un mero cuerpo pasivo objeto de contemplación. Las mujeres de letras, por el contrario, son percibidas como usurpadoras, intrusas en un territorio masculino. Estas consideraciones son necesarias para comprender el valor transformador de las acciones de artistas como Jo Spence, Adela Marín o Shirin Neshat, quienes prestan su propia corporalidad como lienzo en el que plasmar discursos silenciados.

Los estereotipos femeninos difundidos por los medios de comunicación son también motivo de análisis para la profesora Eva María Ramos, a través del estudio de las ilustraciones de los anuncios publicitarios de las revistas españolas de principios del XX. Estas publicaciones fueron coetáneas de una serie de precursoras en la danza moderna como Isadora Duncan, Ruth Saint Denis o Loïe Fuller y coinciden temporalmente con una oleada de orientalismo que también se hizo patente en artistas como Matisse. Estas artistas inspiraron una abundante producción gráfica en multitud de anuncios publicitarios, en los que la mujer, como bailarina exótica y sensual, se convierte en el reclamo del producto. La imagen de la mujer es de nuevo usada como reclamo sexual-comercial, mientras que el dominio del discurso y la palabra siguen siendo masculinos.

Una reflexión acerca de la evolución de los modos de experiencia estética apreciables entre finales del siglo XVII y el siglo XX constituye la aportación del profesor Luis Puelles. Un hito importante a considerar dentro de esta evolución lo constituye la concepción kantiana del sujeto receptor de la obra de arte, caracterizado por un desinterés práctico respecto del objeto de contemplación. Desinterés que le mantiene a salvo de abandonar el examen racional de los valores objetivos del objeto estético para caer cautivo de efectos emocionales. A lo largo del XIX, estos rigores formalistas irán dejando paso paulatinamente a una concepción de la obra artística cada vez más dependiente de una recepción emotiva e intensa, cercana al apasionamiento y la sentimentalización, en lo que Puelles define como un proceso de feminización y democratización de la experiencia estética: ahora el espectador es ella. Unos nuevos modos de recepción que se degustan en escenarios adaptados al sujeto moderno, al que permiten un estimulante aislamiento en público, como el que se experimenta en el café, en el museo o en el palco, lugares desde donde mirar mientras se es mirado.

El volumen deja espacio para mostrar un ejercicio de práctica artística con la reproducción de la serie de dibujos "Todo es mentira, salvo alguna cosa", constitutiva de la exposición Don't Mess With The Mon(k)ey de la artista y profesora de Bellas Artes Isabel Garnelo. La serie proyecta una mirada irónica y reveladora del uso capcioso de imagen y palabra que realizan las instituciones representantes de los poderes contemporáneos, especialmente los financieros. Así termina un trabajo que, a través de sus diversos enfoques, muestra al lector un panorama de subjetividades femeninas que dotan de sentido a una modernidad artística alternativa y desmitificadora. Una luz que contrasta con las sombras de aquella otra modernidad del discurso convencional, cuyo espíritu innovador en tantos frentes convive en demasiadas ocasiones con una injusta visión de la condición femenina. 